\title{
O QUE ACONTECEU COM AS PESSOAS? A DITADURA NOS LIVROS DIDÁTICOS DE HISTÓRIA
}

\author{
WHAT HAPPENED WITH THE PEOPLE? THE DICTATORSHIP IN THE \\ HISTORY TEXTBOOKS
}

\author{
Juliana Pirola da Conceição Balestra ${ }^{1}$ \\ Rogério Anderson da Silva²
}

\begin{abstract}
RESUMO: O artigo apresenta os resultados de uma pesquisa realizada sobre a participação de civis na abordagem da última ditadura brasileira em livros didáticos de História, que circularam no país durante o final do regime e nas primeiras décadas do século XXI. O objetivo é refletir sobre a construção de memórias sobre o período e suas implicações na atualidade, tomando como referência os estudos de Elizabeth Jelin, Michael Pollack e Jörn Rüsen sobre memória, trauma, luto e perdão. Destaca-se que as narrativas que ocultam a participação da sociedade civil durante a última ditadura brasileira escondem os traumas que permanecem latentes na sociedade atual. Com isso, nega-se aos sujeitos, vítimas e algozes, a possibilidade realizar um "luto histórico", onde poderiam reconhecer o passado traumático como parte de sua própria história ou identidade.
\end{abstract}

Palavras-chave: Ditadura. Livro didático. Ensino de história.

ABSTRACT: This article presents the results obtained from a research about the involvement of civilians in the approach of last Brazilian dictatorship in high school history textbooks that circulated in the country during the end of the regime and in the first decades of the $21^{\text {st }}$ century. The objective is to reflect upon the memory construction about the period and its implications these days, based on the studies of Elizabeth Jelin, Michael Pollack and Jörn Rüsen about memory, trauma, mourning and forgiveness. It is important to stand out that the narratives that conceal the participation of civil society during the last Brazilian dictatorship hide the traumas that remain latent in today's society. In this way, victims and executioners are denied the possibility of "historical mourning", where they could recognize the traumatic past as part of their own history or identity.

Keywords: Dictatorship. Textbook. History teaching.

\footnotetext{
${ }^{1}$ Licenciada em História e Doutora em Educação. Atualmente é Professora Adjunta do Curso de História da Unila, onde coordena o Grupo de Pesquisa EducAL

${ }^{2}$ Graduado em História Licenciatura pala Universidade Federal da Integração Latinoamericana - Unila. Tem experiência na área de História, com ênfase em Ensino de História.
}

História \& Ensino, Londrina, v. 25, n. 1, p. 159-182, jan./jun. 2019 


\section{1. $O$ que aconteceu com as pessoas?}

Desde muito jovem convivi com discursos dicotômicos sobre o período da última ${ }^{3}$ ditadura no Brasil, de 1964 a 1985. Meu avô, que foi militar, sempre apontava o caráter negativo da ditadura para o país e para a sociedade, enquanto meu pai, um civil, exaltava os anos da ditadura como uma época em que havia segurança, emprego e crescimento econômico.

Em 2013, quando manifestações populares eclodiram por todo o país e com elas, os pedidos de uma nova intervenção militar, me interessei por investigar como as narrativas sobre a ditadura civil-militar brasileira foram construídas e como o ensino de história contribuiu para a formação de memórias entre as gerações pós 1964. Afinal, as contradições que marcaram minha formação pessoal se apresentavam agora em uma memória pública, como uma espécie de trauma, uma história mal resolvida.

Como os livros didáticos foram muito importantes em minha formação e ainda hoje, seguem como um dos principais instrumentos de divulgação da história nas escolas, iniciei a pesquisa investigando como os livros didáticos ${ }^{4}$ narram o período. Para minha surpresa, entre tantas ausências, não havia relatos de como a ditadura afetou a vida das pessoas no cotidiano e os sujeitos históricos da época se resumiam aos presidentes em exercício e alguns opositores destacados. E as pessoas, o que aconteceu com as pessoas durante o período? Por que a sociedade civil não aparece como

\footnotetext{
${ }^{3}$ O Brasil passou por dois períodos reconhecidos pela historiografia como ditaduras: o primeiro de 1937 a 1945, quando Getúlio Vargas decreta o "Estado Novo" e acaba com os partidos políticos que disputavam vagas no Poder Legislativo. O segundo, de 1964 a 1985, quando as formas armadas em conjunto com setores conservadores da sociedade civil tomam o poder por meio de um golpe e passam a governar com atos institucionais.

${ }^{4}$ De acordo com Circe Bittencourt (2008), os livros didáticos estão na categoria de história a ser ensinada, na relação direta com as normativas curriculares nacionais para a educação no Brasil, podendo servir como um indicador da memória oficial assumida sobre o período. Considerando a materialidade do livro didático, a autora destaca que se trata de um livro cujo destinatário principal é o professor, sujeito que decide sobre sua compra e formas de utilização. O aluno, público-alvo explícito, caracteriza-se por ser o seu consumidor compulsório.
} 
parte desta história ${ }^{5}$ ? De certa forma, fiquei com a sensação de que a história contada nos livros didáticos desumaniza os acontecimentos do período e dificulta a compreensão de que nós também fazemos parte da história, como vítimas, militantes e, sobretudo, como corresponsáveis ${ }^{6}$.

$\mathrm{Na}$ intenção de responder a estas questões, este artigo apresenta os resultados de uma pesquisa realizada em livros didáticos de História que circularam no país durante o final do regime e nas primeiras décadas do século $\mathrm{XXI}^{7}$. O objetivo foi refletir sobre a construção de memórias sobre $\mathrm{O}$ período e suas implicações na atualidade, tomando como referência os estudos de Elizabeth Jelin, Michael Pollack e Jörn Rüsen sobre memória, trauma, luto e perdão.

\section{A ditadura nos livros didáticos de história}

Nos livros didáticos brasileiros, a história de nossa última ditadura costuma aparecer em três momentos específicos: no $5^{\circ}$ e $9^{\circ}$ ano do Ensino Fundamental e no $3^{\circ}$ ano do Ensino Médio, que são exatamente os "anos de conclusão", devido à abordagem cronológica adotada pela maioria dos programas de ensino do país (BALESTRA, 2015). A terminologia frequentemente utilizada é "regime militar pós-64", que não discute a participação dos civis no processo, assim como "ditadura militar" / "golpe militar", e não civil-militar.

Para este artigo, foram selecionados três livros didáticos de História que circularam no país durante o final do regime e nas primeiras décadas deste século. São eles:

- História do Brasil: da Colônia à República, de 1982, assinado por Elza Nadai e Joana Neves pela Editora Saraiva (NADAI; NEVES, 1982);

\footnotetext{
5 Para aprofundar a discussão sobre a ideia de sociedade civil e sua participação no regime estabelecido confira Gramsci (1987) e Dreifuss (1981).

6 Não se trata aqui de opor sujeitos coletivos e individuais na abordagem desses conteúdos, mas de questionar a impessoalidade com que esta história, tão próxima e tão sensível é abordada, dificultando a construção de empatias e identidades.

7 A escolha dos livros foi aleatória e envolveu os materiais disponíveis no Acervo do Laboratório das Licenciaturas da Universidade Federal da Integração Latino-Americana (UNILA).
} 
- História - Uma abordagem integrada, de 2003, assinado por Nicolina Luíza de Petta e Eduardo Aparício Baez Ojeda pela Editora Moderna (PETTA; OJEDA, 2003);

- História Sociedade e Cidadania, de 2013, assinado por Alfredo Boulos Júnior pela Editora FTD (BOULOS JÚNIOR, 2013).

O livro, História do Brasil: da Colônia à República, de 1982, era destinado ao então Segundo Grau, em volume único. No livro, a história da última Ditadura aparece no capítulo "O Brasil Pós-64" e o conteúdo sobre o tema encontra-se exposto em 11 páginas (245 - 256), incluindo a leitura complementar sugerida pelas autoras. O texto produzido por Braz José de Araújo, expõe que dois modelos econômicos estavam em disputa em 1964 e afirma que o sistema econômico que prevaleceu, visava subordinar as massas populares aos interesses de grandes empresas, além de que o regime instalado naquele período tinham importante relação com o desenvolvimento do capitalismo na época e evidencia que para impor esse plano de gestão econômica, a democracia foi cerceada.

Na parte inicial da explanação sobre o tema, as autoras demonstraram que existia certa dificuldade para escrever sobre o período, pois ele ainda estava vigente no país. A única menção à sociedade civil expressa na introdução, resume-se a afirmar que havia "[...] restrições e mesmo o bloqueio completo da participação das bases populares no processo político" (NADAI; NEVES, 1982, p. 245), o que coloca a sociedade civil apenas como vítima do golpe, com isso, a narrativa isenta a população de qualquer participação no golpe efetivado em março de 1964 e na sua perpetuação nos anos seguintes.

Sob o título "1. O golpe de Estado de 1964", Nadai e Neves (1982) passam a descrever os eventos que motivaram e possibilitaram a derrubada do Governo João Goulart. No subtítulo "1.1 condições gerais", são utilizados termos genéricos como "setores conservadores", "classe média", "classe dominante", "grupos de direita", etc., em referência à parte da população brasileira que apoiava os militares. Ao dissertar sobre "1.2 A efetivação do golpe", a única menção a sociedade civil novamente possui caráter genérico 
quando as autoras afirmam que "no Rio de Janeiro, no dia 2 de abril, cerca de 200.000 pessoas desfilaram em uma outra Marcha da Família com Deus pela Liberdade [...]" (NADAI; NEVES, 1982, p. 247).

No decorrer do texto, as referências feitas à sociedade civil a colocam como vítima de um regime repressivo, a qual o Estado procura fazer "a contenção de manifestações populares" e a "eliminação física de pessoas" que se opunham ao regime. O texto narra, portanto, uma história sem sujeitos concretos e oculta a participação dos indivíduos no golpe, e posteriormente, durante a ditadura, desumaniza os fatos ocorridos naquele período. No entanto, é preciso levar em consideração que o livro foi escrito em 1982, ou seja, durante a ditadura civil-militar brasileira. Nesse sentido, deve-se ressaltar que o manual didático também passava pelo crivo do Estado, o que de certa maneira, pode ter orientado as autoras a produzir uma narrativa ausente de sujeitos.

O livro, História - Uma abordagem integrada, de 2003, é destinado ao atual Ensino Médio, também em volume único. No livro, distante 20 anos do anterior, a história da ditadura aparece no capítulo intitulado "O Governo Militar no Brasil (1964 1985)", entre as páginas 284 a 289. Ao referir-se ao golpe, na introdução do capítulo, os autores reduzem a participação da sociedade civil a alguns grupos nacionais, como pode ser observado no seguinte trecho: "Os grupos nacionais que se sentiam ameaçados pelas reformas que João Goulart tentava implantar aliaram-se aos militares, que jamais haviam aceitado" (PETTA; OJEDA, 2003, p. 284). Com isso é possível perceber que diversos setores da sociedade civil são silenciados na narrativa proposta pelo livro. Os nomes dos tais "grupos nacionais" que se sentiram ameaçados pelas reformas em questão, não foram expostos ao público leitor, apagando-se discursivamente sua identidade.

No decorrer do texto, os autores apresentam uma narrativa que descreve o "controle social" exercido pelos militares naquele período. As referências feitas à sociedade civil estão relacionadas aos sujeitos que resistiam ao regime autoritário, chamados de "grupos de esquerda" e os "grupos que combatiam o governo eram denominados subversivos". A única 
menção a civis que apoiaram o regime instaurado resume-se a "empresários paulistas" que financiaram a Operação Bandeirantes (Oban) ${ }^{8}$, em uma narrativa que não menciona sujeitos reais, com nome $e$ sobrenome, mas que estavam envolvidos naquele processo histórico.

No tópico "A sociedade civil contra o militarismo", os autores apresentam recortes de jornais de diferentes momentos ao longo do período para exemplificar o papel da imprensa na resistência ao regime "militar", omitindo que parte da imprensa brasileira, especialmente as de grande circulação nacional, atuaram deliberadamente no apoio ao regime estabelecido. O restante do capítulo segue roteiro semelhante ao do livro produzido por Elza Nadai e Joana Neves no ano de 1982 e utiliza categorias genéricas para se referir às pessoas que de alguma forma estavam envolvidas naquele processo histórico. Nesse sentido, não basta dizer que houve participação de certos "grupos nacionais" no golpe e, posteriormente no regime, é preciso evidenciar de que forma esses grupos atuaram e quais eram os interesses. Dessa forma, seria possível que os leitores do livro se apropriassem de uma narrativa mais complexa dos fatos ocorridos naquele momento histórico.

Outro livro analisado foi "História - Sociedade e Cidadania", de 2013, que também é destinado ao Ensino Médio, assinado por Alfredo Boulos Júnior e publicado com uma década de diferença do livro anterior e três décadas do primeiro livro analisado.

No livro, o autor usa o conceito de "regime militar" para se referir a ditadura civil-militar brasileira. O conteúdo sobre o tema encontra-se distribuído da página 206 a 222, especificamente no capítulo 11 que é o penúltimo do livro. Ao iniciar o capítulo, o autor faz uma breve introdução expondo de forma categórica que se tratava de uma "ditadura militar", ao descrever da seguinte maneira o evento: "Com o golpe que derrubou João Goulart em abril de 1964, os militares tomaram o poder político e nele

\footnotetext{
${ }^{8}$ A Operação Bandeirantes (OBAN) foi criada pelo II Exército em São Paulo no mês de julho de 1969, foi um centro integrador das forças de repressão do regime ditatorial. Tornou-se um dos órgãos mais violentos da ditadura, por suas instalações passam aproximadamente 10.000 prisioneiros.
} 
permaneceram por 21 anos. Daí a expressão regime militar para designar aquele período" (BOULOS JUNIOR, 2013, p. 207). Assim, como os demais livros analisados, a participação de civis no golpe e, posteriormente, na manutenção do regime é anonimizada, o que isenta parte da sociedade civil da responsabilidade de cooperar com os militares para a efetivação do golpe e na sustentação do regime que perdurou tanto tempo.

No tópico, "militares no poder", Boulos Junior (2013) descreve os acontecimentos políticos do período e os "Atos Institucionais" (AI's), além de escrever sobre as questões econômicas do período como "aumento de impostos, empréstimos volumosos, incentivo a entrada de capital estrangeiro", etc. Em relação aos eventos que envolviam diretamente a sociedade civil, o autor menciona a "violenta repressão contra pessoas, grupos e órgãos ligados ao governo anterior" e também que "estudantes e jornalistas foram duramente atingidos" (BOULOS JUNIOR, 2013, p. 207). Novamente, a sociedade civil é apresentada como vítima das ações violentas dos militares e se oculta a participação efetiva de agentes civis no desenvolvimento e funcionamento dos mecanismos repressivos.

Helenice Rocha (2015), que também investigou a presença desta temática em livros didáticos de História, afirma que na década 1970 não há qualquer menção à palavra "ditadura" nos livros didáticos do período. Segundo a autora, os títulos e menções ao acontecimento tratam o período como integrado à chamada "República Nova", iniciada em 1930 ou a partir de 1945. A menção ao golpe é feita como "Deposição de João Goulart pelas Forças Armadas" ou "O Movimento de 31 de março de 1964". Segundo a autora, em alguns manuais, o período militar é apresentado como "A redemocratização do país" e o golpe recebe o nome de "Revolução Gloriosa".

Essas disputas de sentido na escolha de termos para nomear e significar o regime estabelecido e sua forma de ascensão ao poder revela que, assim como as pessoas, os termos e conceitos também tem história (s), com autores, intenções e disputas por sua significação (KOSELLECK, 1992). Nesse sentido, eles trazem consigo um significado que vai além da 
linguagem, expressam o contexto de uma determinada época. Portanto, um conceito não é apenas a semântica de uma palavra, e sim "[...] um emaranhado de perguntas e respostas, textos/contextos" (KOSELLECK, 1992, p. 137), ou seja, um objeto de exaustiva teorização. Por isso, é necessário que o conceito a ser utilizado em uma narrativa consiga abarcar ao máximo os fatos ocorridos.

Nos livros didáticos, o emprego da expressão "ditadura militar" para se referir à última ditadura no Brasil ofusca a participação civil nesse evento e dificulta o entendimento de que naquela época, assim como agora, a sociedade civil é corresponsável pelos acontecimentos políticos e sociais de nossa história.

\section{A participação de civis na história da ditadura}

As Ditaduras civil-militares de Segurança Nacional ${ }^{9}$ atravessaram de maneira distinta diversos países da América Latina, tanto em extensividade quanto em intensividade, o que certamente interfere nos modos de se relacionar com ela (BAUER, 2011). No Brasil, a última ditadura permaneceu vinte e um anos no poder (1964-1985), caso se considere o ano de 1985 e a posse de José Sarney como marcos democráticos no processo de transição política. Durante esse período, milhares de pessoas "desapareceram"10 e o trauma gerado na sociedade brasileira segue latente na atualidade, ainda que já se tenha passado mais de cinquenta anos dos fatos ocorridos, por sua carga singular de dor e violência. Além disso, essa história ainda ativa lutas no presente, crimes ainda não foram julgados; milhares de corpos não foram sepultados e muitos amigos e familiares seguem na busca por informações sobre companheiros, parentes e amigos.

\footnotetext{
9 Para mais informações sobre o conceito de Ditadura civil-militar de Segurança Nacional confira Padrós (2007), Pomar (2012) e Moraes (2012).

10 Embora o número oficial de mortos e desaparecidos do regime brasileiro não compreenda mais do que 500 nomes, estima-se que cerca de 10.000 pessoas foram assassinadas pelo regime, entre indígenas, quilombolas, militantes políticos e demais grupos estigmatizados como subversivos ou perigosos.
} 
$\mathrm{Na}$ luta contra o esquecimento, movimentos sociais seguem isolados batalhando por verdade e justiça (BAUER, 2011).

O modo como se efetivou a transição democrática no país teve grande influência na elaboração dessas políticas de (des) memória ${ }^{11}$. No Brasil, a transição foi totalmente controlada pelos militares e pactos de silêncio impedem o acionamento da justiça. Além disso, a ideia de anistia como apagamento do passado contribuiu para a consolidação de práticas educativas que silenciam sobre o período ${ }^{12}$. Assim, consolidou-se a ideia de que a melhor política sobre o passado é aquela que não existe (BAUER, 2011). Mas, de nenhum modo, isso significa um descaso com a história recente, muito pelo contrário, pois o esquecimento também tem finalidades políticas. "[...] Não o esquecimento voluntário, relacionado à necessidade individual ou coletiva de 'seguir adiante', mas sim de um esquecimento induzido, o silenciamento [...]" (CAVÍGLIA apud BAUER, 2011, p. 223).

Nesse sentido, há décadas, diversas pesquisas deixam cada vez mais evidentes a responsabilidade ampliada pela implantação e manutenção do regime, que mesmo protagonizado por militares, contava com o apoio e financiamento de diferentes setores da sociedade, como aponta Daniel Aarão Reis:

Evidencia-se nesses artigos, dissertações e teses, a participação de jornalistas, advogados, homens de letras, universitários (professores e funcionários), políticos de diversas extrações, artistas conhecidos, movimentos e entidades sociais na construção do regime ditatorial, incluindo-se aí, embora esse "canteiro" ainda esteja pouco explorado, importantes segmentos sociais, inclusive populares, como bem demonstrado especialmente nas pesquisas citadas de Aline Presot, Janaína Cordeiro e Gustavo Alonso. Segundo achados recentes da Comissão Nacional da Verdade (CNV), amplamente noticiados pela

\footnotetext{
${ }^{11}$ Eduardo Galeano (2002) ao referir-se aos regimes democráticos emergidos após as ditaduras afirma que: "[...] a democracia, que tem medo de recordar, nos adoece de amnésia [...]". Portanto, o conceito de (des)memória refere-se a política de esquecimento adotado pelo Estado brasileiro após a transição para a democracia, cujo possível intuito fosse induzir parte da sociedade brasileira a esquecer das violências cometidas pelo Estado contra sua própria população.

12 Para ampliar a discussão sobre o papel da anistia na construção de memórias sobre o período confira Teles e Safatle (2010) e Pinheiro (2014).
} 
imprensa, até num setor específico, onde se presumiria a exclusiva participação de militares ou de policiais, o aparelho repressivo nucleado em torno dos Centros de Operações de Defesa Interna (CODIs), se elucida a participação de civis na organização, no financiamento e nas operações do referido aparelho (REIS, 2015, p. 240-241).

Segundo o autor, ao concordarmos que a ditadura no Brasil foi apenas militar, automaticamente aceitamos que todos os civis faziam parte da oposição a ela e apaga-se do cenário os civis "que se beneficiaram do regime ditatorial. Os que financiaram a máquina repressiva. Os que celebraram os atos de exceção" (REIS, 2015, p. 3).

Sabe-se que as "Marchas da Família com Deus pela Liberdade" mobilizaram milhares de pessoas contra as reformas propostas pelo então presidente João Goulart e que delas participaram setores conservadores da sociedade, entre elas, lideranças empresariais, políticas e religiosas e também entidades civis organizadas, como a Ordem dos Advogados do Brasil $(O A B)$ e a Conferência Nacional dos Bispos do Brasil (CNBB) que balizavam a tomada do poder pelos militares em 1964. No dia seguinte ao golpe, em 02 de abril de 1964, realizou-se no Rio de Janeiro a "Marcha da Vitória" para comemorar o "triunfo" dos militares, ou seja, ainda que não se tivesse clareza do que estava por vir, diversos setores da sociedade civil brasileira estavam alinhados com os interesses do grupo protagonizado pelos militares e apoiaram suas ações.

No Relatório produzido pela Comissão Nacional da Verdade (BRASIL, 2014a), destaca-se que a ditadura brasileira não se sustentaria por mais de duas décadas sem o apoio de importantes setores da sociedade civil ${ }^{13}$. Segundo o Relatório, civis foram responsáveis por financiar diversas instituições de repressão do Estado, como o Instituto de Pesquisas e Estudos Sociais (IPES) por exemplo, que "resultou de uma interação entre empresários e tecnoempresários, políticos conservadores e membros da alta hierarquia das Forças Armadas" (BRASIL, 2014a, p. 316). O Relatório

13 Para aprofundar a discussão sobre a participação de empresários no golpe e manutenção do regime confira Campos (2014). 
aponta que o IPES surgiu do contato entre o empresário brasileiro Paulo Ayres Filho e o norte-americano Gilbert Huber Jr., com a intenção de promover campanhas de desestabilização do governo do então presidente João Goulart.

Por outro lado, muitos empresários sofreram perseguições por não compactuarem com o regime estabelecido. De acordo com a CNV os empresários que defenderam a Constituição "[...] foram perseguidos e punidos pelo regime ditatorial" (BRASIL, 2014a, p. 325). Um caso exemplar, segundo o Relatório, foi o dos empresários Mário Wallace Simonsen e Celso Rocha Miranda que controlavam a empresa PANAIR DO BRASIL, uma das maiores empresas privadas do país e símbolo da aviação comercial brasileira, que teve suas atividades encerradas ainda em 1964 por um "decreto arbitrário" do então comandante da nação, o general Castelo Branco. Ainda assim, em 1965, um juiz da 6a Vara Cível da Justiça decretou a falência da empresa, o que demonstra que mesmo entre os setores empresariais não havia uma homogeneidade para apoiar o golpe e, posteriormente, o regime.

Na última década do regime ditatorial, quando a censura já havia se consolidado como prática comum nas instituições públicas e nos meios de comunicação, eram civis que protagonizavam os mecanismos de censura do Estado, como aponta Carlos Fico (2002). Segundo o autor, entre os anos de 1976 a 1980, membros da sociedade civil enviaram mais de 200 cartas para a Divisão de Censura de Diversões Públicas (DCDP), cobrando medidas punitivas aos meios de comunicação por exibirem conteúdos que supostamente atentavam contra os valores morais da época, especialmente nas questões relacionadas à sexualidade. De certa forma, isso evidencia que parte da sociedade civil brasileira se identificava com as práticas de censura realizadas pelo Estado e contribuía com sua manutenção, denunciando os supostos violadores da "moral e bons costumes".

Enquanto isso, grande parte da sociedade civil procurava se isentar de qualquer posicionamento por meio de uma série de "deslocamentos de sentido", como aponta Bauer (2011), que ajudaram a construir a imagem 
da sociedade como vítima inocente das estratégias de violência implementadas por militares e militantes, o que deu origem à chamada "teoria dos dois demônios"14. Essa teoria tem sido sistematicamente combatida por pesquisadores e movimentos relacionados à luta pelos direitos humanos. Em primeiro lugar, porque iguala em termos de responsabilidade as ações de alguns grupos políticos e organizações armadas com o aparato repressivo ilegal do Estado. Em segundo lugar, porque oferece a imagem de uma sociedade, ou de uma maioria supostamente alheia e ausente às lutas políticas e sem nenhum tipo de responsabilidade na instalação e sustentação do terror perpetrado pelo Estado.

Os Militares também não são, nem nunca foram, uma categoria homogênea. Muitas narrativas históricas produzidas dentro e fora da academia, ao evidenciar o protagonismo de militares na articulação e manutenção do golpe, desconsideram os diversos agentes que também foram presos, cassados e "desaparecidos" durante o regime por aturarem na resistência democrática. De acordo com estudos preliminares da CNV, disponíveis no site da Comissão (BRASIL, 2014b), os militares representam o grupo social urbano mais atingido pela repressão, com cerca de 7000 vítimas, sendo que 37 foram vítimas fatais e outras tantas tiveram seus direitos políticos e sociais restritos.

Um dos casos mais emblemáticos é o do coronel da aeronáutica, Alfeu de Alcântara Monteiro que se recusou a apoiar o golpe contra João Goulart e foi assassinado na Base Aérea de Canoas (RS), em 4 de abril de 1964, com tiros de metralhadora pelas costas dentro do seu próprio gabinete; da mesma forma, o capitão José Araújo Nóbrega sofreu perseguições, foi preso e torturado por ser acusado de envolvimento com o Movimento Nacional Revolucionário e a Vanguarda Popular Revolucionária. Ainda que o objetivo não seja destacar os militares como vítimas do processo ditatorial, é preciso ressaltar que as categorias sociais envolvidas nas narrativas sobre o período

\footnotetext{
${ }^{14}$ Tratava-se, assim, de uma representação confortável para a sociedade, que se colocava externamente a esse conflito, em uma posição de inocência e não-responsabilidade pela violência. (QUINALHA, 2013, p. 191).
} 
não são homogêneas. Quanto à participação de civis na organização e manutenção do regime ditatorial, em foco neste trabalho, acredita-se que os deslocamentos e silenciamentos sobre a sua participação são o reflexo da carga traumática deste passado recente para os brasileiros.

\section{Trauma, luto e perdão na história da ditadura}

Elizabeth Jelin (2001), ao referir-se às memórias sobre a repressão política no Cone Sul, afirma que "en la situación extrema de ruptura y confusión, no se encuentran las palabras para expresar y representar lo sucedido y estamos frente a manifestaciones del trauma" (JELIN, 2001, p. 15). Segundo a autora, as situações traumáticas impõem dificuldades de explicação para a cultura histórica e os momentos de crise dentro de um grupo ou de uma sociedade podem forçar a reflexão sobre o passado, o que acarretaria questionamentos sobre a identidade e coesão do grupo social. Para a autora, são nesses momentos "[...] que puede haber una vuelta reflexiva sobre el pasado, reinterpretaciones y revisionismos, que siempre implican también cuestionar y redefinir la propia identidad grupal" (JELIN, 2001, p. 8).

Da mesma forma, Jörn Rüsen (2009), refletindo sobre a experiência do Holocausto na Alemanha, aponta que os traumas são eventos históricos que a cultura histórica não consegue explicar por meio das estratégias existentes. Tais eventos têm caráter destrutivo e, por trazerem à tona fraturas da civilização moderna são difíceis de serem superados. Assim como Jelin (2001), Rüsen (2009) afirma que é preciso uma "crise" para impulsionar novas interpretações históricas ou a reinterpretação de um passado traumático. Pois é na necessidade de superar uma "crise", que os padrões de explicações dados pela cultura histórica são questionados, fazendo com que seja necessário recorrer à reflexão histórica para suplantar tal "crise".

Na mesma perspectiva, Michael Pollack (1989) acrescenta que os sujeitos enfrentam múltiplas dificuldades para aceitar os eventos negativos 
como parte de sua própria história e as narrativas oficiais impõem a fronteira entre o "dizível e o indizível, o confessável e o inconfessável", na pretensão de marginalizar a "uma memória coletiva subterrânea". Com isso, o que se divulga é uma memória coletiva organizada que resume a imagem que uma sociedade majoritária ou que o Estado deseja passar e impor (POLLAK, 1989, p. 8). No entanto, afirma o autor, as "memórias subterrâneas que prosseguem seu trabalho de subversão no silêncio e de maneira quase imperceptível afloram em momentos de crise em sobressaltos bruscos e exacerbados" (POLLAK, 1989, p. 5) De acordo com o autor, as memórias subterrâneas de eventos traumáticos seguem preservadas em meio as lacunas deixadas pelas narrativas oficiais, aguardando momento oportuno para eclodirem. Nesse sentido, "o silêncio sobre o passado, longe de conduzir ao esquecimento", reforça as resistências, especialmente daqueles que "transmitem cuidadosamente as lembranças dissidentes nas redes familiares e de amizades, esperando a hora da verdade e da redistribuição das cartas políticas e ideológicas" (POLLAK, 1989, p. 5).

Os estudos elaborados por Jelin sobre a memória atribuem aos sentimentos e emoções papel significante nas indagações sobre o sentido que é atribuído ao passado perturbador. Segundo a autora, "Allí se juegan los afectos y sentimientos, que pueden empujar a la reflexión y a la búsqueda de sentido. [...] El acontecimiento o el momento cobra entonces una vigencia asociada a emociones y afectos, que impulsan una búsqueda de sentido" (JELIN, 2001, p. 9). Essas questões contribuem para que o passado traumático seja incorporado ao sujeito no processo de construção ou reconstrução de sua identidade.

Já Rüsen (2009) afirma que para perder sua carga traumática, o passado precisa ser historicizado e dar lugar a novas interpretações que devem ser incorporadas pela cultura histórica na perspectiva de uma consciência histórica. Para Rüsen, atualmente a história possui diversas estratégias destraumatizantes para lidar com os elementos perturbadores dos traumas (RÜSEN, 2009, p. 196-198): 
1. Anonimização: ao invés de falar de assassinatos e crimes, de sofrimento por uma falha ou culpa, menciona-se algo como "período de trevas", uma ruptura em um mundo mais ou menos ordeiro;

2. Categorização: o trauma é contextualizado por meio de ocorrências e processos compreensíveis. Para aqueles que estão envolvidos - mas não só, ele perde sua singularidade perturbadora ao ser referido por termos abstratos dotados de significado.

3. Normalização: dissolve-se a qualidade destrutiva do evento ao apresentá-lo como algo recorrente, arraigado na natureza humana, que acontece o tempo todo e em todos os lugares;

4. Oralização: o evento traumático adquire o caráter de um caso, dissociado das ações humanas de indivíduos, e representa uma regra geral da conduta humana com uma mensagem claramente moralista aos observadores ("não faça uma coisa dessas!");

5. Estetização: apresenta as experiências traumáticas para os sentidos de forma moderada e compreensível, como um quadro que o torna, no pior dos casos, pronto para consumo.

6. Teleologização: reconcilia o passado com o presente por meio da legitimidade e aceitação. Uma lição é aprendida e o trauma se dissolve em um processo de aprendizagem usado para legitimar historicamente uma ordem de vida que afirma prevenir seu retorno e oferecer proteção contra ele;

7. Reflexão meta-histórica: o evento traumático é reconhecido como parte da história e apresentado de forma conceitual e abstrata, incorporado a uma cadeia de eventos no fluxo do tempo vivido, destacando as mudanças temporais. Assim, a dolorosa factualidade dos eventos traumáticos se evapora no ar impalpável da abstração.

8. Especialização: divide-se o evento traumático em diferentes aspectos que se tornam assuntos específicos para especialistas diferentes e, por meio da fragmentação, desaparece a dissonância perturbadora da totalidade do quadro histórico - um meio acadêmico genuíno de manter sob controle a ausência de sentido das experiências traumáticas. 
Para Rüsen (2009), com tais estratégias historiográficas, as histórias de experiências violentas têm sido contadas ao longo do tempo de forma alienante, já que se criam narrativas sobre o passado com o objetivo de "aliviar" seus traços mais traumáticos. No entanto, afirma o autor, na vida prática esses traços se mantêm vivos e em momentos de crise são facilmente descobertos sob a superfície da memória coletiva. Para que a história possa enfrentar esses traumas e elaborar seu próprio luto, Rüsen (2009) defende que é preciso mudar o modo de fazer história: ao invés da "destraumatização", o novo paradigma deve considerar uma "traumatização secundária", que reconheça o trauma como parte constitutiva da narrativa histórica. Segundo o autor, os eventos traumáticos deixam traços no próprio padrão de significância do trabalho de interpretação dos historiadores e é preciso manifestar sua perturbação e dar-lhe visibilidade:

- ao invés da anonimização, deveria claramente ser dito o que aconteceu por meio da chocante nudez da factualidade rude;

- ao invés de subjugar os eventos às categorias dotadas de sentido, os eventos deveriam ser situados em padrões interpretativos que problematizem as categorias tradicionais de sentido histórico;

- ao invés de normalizar a história como dissolvente dos elementos destrutivos, deve-se manter a memória da 'normalidade da exceção'. Devem ser relembrados o horror embaixo da fina capa da vida cotidiana, a banalidade do mal etc.;

- ao invés de moralizar, a interpretação histórica precisa indicar os limites da moralidade, ou melhor, sua fragilidade interna;

- ao invés de estetizar, a interpretação histórica deveria enfatizar a brutal feiura da desumanização;

- ao invés de suavizar experiências traumáticas pela teleologia, a história deve apresentar o fluxo do tempo como sendo obstruído na relação temporal entre o passado dos eventos traumáticos e a presença de sua comemoração. Descontinuidade, rompimento de conexões e destruição tornaram-se características de sentido na idéia geradora de sentido do curso do tempo.

- Eventualmente, a reflexão metahistórica precisa assumir toda a dimensão traumática dos elementos perturbadores da experiência histórica e conduzi-los à abstração das noções e das idéias. 
- A especialização, por fim, precisa ser novamente conectada com um "arcabouço interpretativo abrangente e convincente" (RÜSEN, 2009, p. 200).

O luto, nesse sentido, refere-se à perda da própria humanidade que se vê refletida nesses eventos traumáticos. Rüsen (2009) afirma que o luto e a história têm uma essência comum por ambos serem um procedimento da memória e estarem comprometidos com a lógica de geração de sentido para um passado traumático. O luto traz de volta a lembrança de algo especial que foi perdido (objeto ou pessoa), nesse processo mental o indivíduo revive, remonta a perda em forma de ser ancestral, quando se trata da perda de uma pessoa. O caminho mais fácil e frequentemente praticado pelo luto histórico é o de esquecer os eventos que devem ser moralmente condenados, vistos como ameaça por evidenciar que atuamos não só como vítimas, mas também como algozes. No entanto, as memórias subterrâneas perpetuam sua existência e com isso o passado segue determinando o presente de modo inquestionável. O passado é constantemente revivido e os mortos permanecem vivos e ativos no presente. Os eventos passados não são esquecidos. São passados que não passam.

Para superar o trauma, Rüsen (2009) afirma que é preciso vivenciar o luto e tomar consciência da experiência de perda da humanidade das vítimas e de seus violadores e responsabilizar-se pelos atos desumanizadores, recuperando assim a humanidade perdida. No contexto dos livros didáticos, as narrativas históricas sobre a última ditadura do Brasil deveriam ocupar-se menos de conceitos abstratos e expor tanto as violações cometidas por agentes civis e militares, como a forma com que os discursos oficiais narram o período e os traumas produzidos por essas experiências na memória coletiva. Adotar uma nova perspectiva de narrativa histórica, na qual os eventos traumáticos sejam evidenciados à luz da nudez de seus fatos, significa romper com um modelo de história que propunha, como lembra Jelin (2001, p. 13), "el olvido (político) de lo 
singular y único de una experiencia, para tornar más productiva a la memoria oficial".

Segundo Rüsen (2009), com isso evita-se que o sofrimento das vítimas e a alegria dos violadores sejam colocados dentro de uma normalidade histórica. Porém, para Jelin esse modelo de narrativa histórica só ocorrerá se quem faz história, ouvir o que as fontes têm a dizer: "[...] es necesario encontrar del otro lado la voluntad de escuchar [...] Encontrar a otros con capacidad de escuchar es central en el proceso de quebrar silencios" (JELIN, 2001 , p. 12). Assim, ambas as partes poderiam reconhecer o passado traumático como parte de sua própria história, de sua identidade, e abrir espaço para perdoar (RÜSEN, 2009). O perdão, neste caso, não se trata de anistia ou apagamento do passado, mas de reconciliação a partir do reconhecimento, julgamento e retratação pelos crimes cometidos.

As narrativas que ocultam a participação da sociedade civil durante a última ditadura brasileira escondem os traumas que permanecem latentes na sociedade atual. De certa forma é negada aos sujeitos, vítimas e algozes, a possibilidade realizar o "luto histórico", onde poderiam reconhecer o passado traumático como parte de sua própria história ou identidade.

Nesse sentido, os livros didáticos de história, ao ocultar que parte da sociedade civil era conivente e corresponsável pelas constantes violações dos direitos humanos promovidos por agentes públicos e civis durante a última ditadura civil-militar no Brasil, impede que os violadores sejam responsabilizados por seus atos e que essa história seja incluída na construção de novas identidades. Isso também impossibilita que o Estado brasileiro, junto com os sujeitos que transgrediram a dignidade humana, possam promover ações de justiça que visem de alguma maneira restituir a humanidade perdida durante os anos em que o autoritarismo prevaleceu no país.

Reconhecer a participação de civis no período e identificar quais membros da sociedade civil apoiaram a manutenção do regime ditatorial pode ser um avanço considerável na tentativa de compreender de forma 
mais ampla a complexidade das relações mantidas entre militares e civis naquele período. Portanto, aceitar que civis que atuaram junto ao regime permitirá que novas interpretações históricas sejam integradas à cultura histórica, refutando assim as narrativas que colocam a sociedade civil apenas como vítima inocente da violência promovida por militares e militantes, para possibilitar que a sociedade elabore o luto histórico.

O processo de luto sobre os anos da ditadura no Brasil por sua vez, passa pelo reconhecimento de que sujeitos reais agiram ativamente em prol das violações cometidas pelo Estado contra sua própria população. O que caracterizaria uma ruptura da cultura histórica dominante, pois evidenciaria o caráter traumático daquele período. Em contrapartida, proporcionaria as condições necessárias para que as memórias subterrâneas pudessem emergir e ocupar seu espaço dentro da memória coletiva. Nesse sentido, violadores e vítimas poderiam reconhecer-se como sujeitos desse processo histórico. Isso implica a assunção da violação dos direitos humanos como parte de nossa história.

Nesse sentido, a cultura histórica deve assumir que os regimes autoritários são construídos por seres humanos reais, onde o perdão só poderá ser alcançado por meio do reconhecimento do sofrimento causado às vítimas das diversas formas de violência promovidas pelo Estado e seus apoiadores. Se o processo de "luto histórico" for bem-sucedido, as graves violações aos direitos humanos serão incorporadas às narrativas oficiais, superando as políticas de esquecimento que por muito tempo predominaram no país.

\section{Algumas considerações}

As memórias que apontam o envolvimento de civis na última ditadura do Brasil vieram à tona em dois momentos principais, que de certa forma provocaram "crises" nas narrativas oficiais que há décadas silenciavam sobre o assunto. A primeira está relacionada à Comissão Nacional da Verdade (CNV), que a partir de 2010 deu visibilidade à participação de civis 
no golpe e manutenção do regime. A segunda, por sua vez, se faz evidente a partir 2013, quando centenas de pessoas que participavam de manifestações contra o governo de Dilma Rousseff começaram a pedir a volta da "ditadura militar", mostrando como a sociedade civil pode ser corresponsável pelo autoritarismo que se impõe.

Nesse sentido, cabe indagar se foi a CNV que gerou essa "crise" e possibilitou o descortinamento das memórias subterrâneas sobre a última ditadura ou se foram essas memórias subterrâneas, há muito tempo reprimidas, que forçaram o surgimento da CNV. Da mesma forma, há que se refletir se as memórias que enaltecem o período e pedem a sua "volta" não vieram à tona em 2013, exatamente porque estávamos sob o governo de uma mulher que militou contra o regime e foi torturada durante o período.

São questões difíceis de serem respondidas. Em todo caso, é inegável que a CNV deu voz às pessoas e aos grupos sociais que até então eram silenciados pela história oficial e expôs para a sociedade brasileira, a intensa cooperação entre civis e militares no golpe de 1964 e, posteriormente, na manutenção do regime, desmistificando a ideia da sociedade civil apenas como vítima da violência cometida pelo Estado. Este é um passo importante para superarmos o trauma desse passado recente e entender o momento que estamos vivendo agora.

Muitos dos atores políticos citados seguem ativos na política brasileira e qualquer reconciliação com este passado deve passar, necessariamente, pela responsabilização dos envolvidos, não envolve apenas o julgamento dos crimes cometidos, mas a inclusão dessas narrativas, antes silenciadas, na construção de memórias coletivas promovidas pelo ensino de história nas escolas.

O uso recorrente de categorias abstratas como: "guerrilheiros"; "comunistas"; "grupos de empresários"; "setores mais conservadores"; "jornalistas"; "setores do clero católico"; "Ordem dos Advogados do Brasil"; "Associação Brasileira de Imprensa"; "estudantes"; "trabalhadores" "movimento sindical"; "organizações civis"; entre outras, desumaniza os 
acontecimentos e silencia as histórias de pessoas reais, com nome e sobrenome, tanto na resistência quanto no apoio a ditadura. Isso dificulta qualquer reparação ou reconciliação com esse passado e impede que as gerações futuras se identifiquem com essas histórias e incorporem essas narrativas como parte de sua própria história.

O grande problema é que desconhecer este passado torna possível, no presente, o surgimento de grupos que são favoráveis ao retorno dos militares ao poder. Ao analisar os acontecimentos recentes no país, evidencia-se que os traumas da ditadura seguem vivos em nossa sociedade, onde as várias denúncias de corrupção e fraudes nas instituições democráticas promoveram o surgimento de um saudosismo que flerta com o militarismo, mais especificamente, parte da sociedade brasileira pede uma intervenção militar para restabelecer a ordem no país.

Com a lei da Anistia e a redemocratização do país, as políticas educacionais do Brasil, especialmente no ensino de história, foram pautadas pela lógica da desmemória. Acreditou-se que a melhor forma de superar as violações promovidas pelo regime militar em associação com membros da sociedade civil era "esquecer" desse passado. No entanto, para que tenhamos um regime democrático consolidado é urgente que o ensino de história se aproprie das novas interpretações historiográficas e tome partido, expondo para as novas gerações as graves violações cometidas contra os direitos humanos durante a última ditadura no país.

Vera Carnovale e Alina Larramendy, ao refletirem sobre o ensino de história da última ditadura na Argentina, afirmam que o educando deve ter acesso "Una Historia que, en el abordaje de los conflictos que caracterizaron al pasado reciente, atienda a la pluralidad de actores en juego, a sus respectivos intereses, intencionalidades, ideologías, prácticas, etcétera" (CARNOVALE; LARRAMENDY, 2010, p. 246).

Os novos relatos e evidências sobre a participação de civis em apoio ao regime ditatorial no Brasil publicizados por meio da CNV expõem a complexidade das relações que envolvem os agentes do Estado e a sociedade civil. Cabe agora ao ensino de história incorporar essas narrativas 
na construção de histórias e interpretações mais amplas e significativas sobre esse passado traumático, tão próximo e tão violento.

\section{Referências}

BALESTRA, Juliana Pirola da Conceição. O peso do passado: currículos e narrativas no ensino de história das Ditaduras de Segurança Nacional em São Paulo e Buenos. 2015. 226 f. Tese (Doutorado em Educação) Faculdade de Educação, Universidade Estadual de Campinas, Campinas, 2015.

BAUER, Caroline Silveira. Um estudo comparativo das práticas de desaparecimento nas ditaduras civil-militares argentina e brasileira e a elaboração de políticas de memória em ambos os países. 2011.446 f. Tese (Doutorado em História) - Instituto de Filosofia e Ciências Humanas Programa de Pós-graduação em História, Universidade Federal do Rio Grande do Sul, Porto Alegre, 2011.

BITTENCOURT, Circe Maria Fernandes. Livro didático e saber escolar 18101910. Belo Horizonte: Autêntica, 2008.

BOULOS JÚNIOR, Alfredo. História sociedade \& cidadania. São Paulo: FTD, 2013.

BRASIL. Comissão Nacional da Verdade. Civis que colaboraram com a ditadura: relatório: textos temáticos. Brasília: CNV, 2014a.

BRASIL. Comissão Nacional da Verdade. Militares relatam opressão antes e depois da ditadura. 2014b. Disponível em:

http://cnv.memoriasreveladas.gov.br/outros-destaques/465-militaresrelatam-opressao-antes-e-depois-da-ditadura.html. Acesso em: 12 ago. 2017.

CAMPOS, Pedro Henrique Pedreira. Estranhas catedrais: as empreiteiras brasileiras e a ditadura civil-militar, 1964-1988. Niterói: Eduf, 2014.

CARNOVALE, Vera; LARRAMENDY, Alina. Enseñar la historia reciente en la escuela: problemas y aportes para su abordaje. In: SIEDE, Isabelino (coord.). Ciencias sociales en la escuela. Buenos Aires: Aique, 2010.

DREIFUSS, René Armand. 1964: a conquista do estado. Petrópolis: Vozes, 1981.

FICO, Carlos. "Prezada censura": cartas ao regime militar. Topoi, Rio de Janeiro, n. 5, p. 251-286, set. 2002.

GALEANO, Eduardo. O livro dos abraços. 9. ed. Porto Alegre: L\&PM, 2002. 
GRAMSCI, Antonio. Cartas do cárcere. 3. ed. Rio de Janeiro: Civilização Brasileira, 1987.

JELIN, Elizabeth. ¿De qué hablamos cuando hablamos de memorias? In: JELIN, Elizabeth. Los trabajos de la memoria. Espanha: Siglo Veinteuno, 2001.

KOSELLECK, Reinhart. Uma história dos conceitos: teóricos e práticos. Estudos Históricos, Rio de Janeiro, v. 5, n. 10, p. 134-146, 1992.

MORAES, João Quartim. Sobre o "aprimoramento" da expressão ditadura militar. Vermelho, 3 set. 2012.

NADAI, Elza; NEVES, Joana. História do Brasil: da colônia a república. 3. ed. São Paulo: Saraiva, 1982.

PADRÓS, Enrique Serra. América Latina: ditaduras, segurança nacional e terror de estado. Revista História \& Luta de Classes, São Paulo, n. 4, jul. 2007.

PETTA, Nicolina Luiza; OJEDA, Eduardo Aparicio Baez. História: uma abordagem integrada. 2. ed. São Paulo: Moderna, 2003.

PINHEIRO, Milton. Ditadura: o que resta da transição. São Paulo: Boitempo, 2014.

POLLAK, Michael. Memória, esquecimento, silêncio. Estudos Históricos, Rio de Janeiro, v. 2, n. 3, p. 3-15, 1989.

POMAR, Pedro. O modismo "civil-militar" para designar a Ditadura Militar. Brasil de Fato, São Paulo, 10 ago. 2012.

QUINALHA, Renan Honório. Com quantos lados se faz uma verdade? Notas sobre a Comissão Nacional da Verdade e a "teoria dos dois demônios". Revista Jurídica da Presidência, Brasília, v. 15 n. 105, p. 181-204, fev./maio 2013.

REIS, Daniel Aarão. Ditadura no Brasil entre memória e história. In: MOTTA, Rodrigo Pato Sá. Ditaduras militares: Brasil, Argentina, Chile e Uruguai. Belo Horizonte: UFMG, 2015.

ROCHA, Helenice. A Ditadura Militar (1964-1985) nas narrativas didáticas. Espacio, Tiempo y Educación, Salamanca, v. 2, n. 1, p. 97-120, jan./jun. 2015.

RÜSEN, Jörn. Como dar sentido ao passado: questões relevantes de metahistória. Revista História da Historiografia, Ouro Preto, n. 2, p. 163-209, mar. 2009. 
TELES, Edson; SAFATLE, Vladimir. O que resta da ditadura. São Paulo: Boitempo, 2010.

Recebido em 29 de outubro de 2018

Aprovado em 29 de março de 2019 